\title{
LAYER FORMATION IN CUNi/C X-RAY OPTICS
}

\author{
A. F. Jankowski \\ D. G. Stearns \\ This paper was prepared for submittal to \\ 1990 Fall Meeting of the \\ Materials Research Society \\ in Boston, MA on November 26-December 1, 1990.
}

November 1990

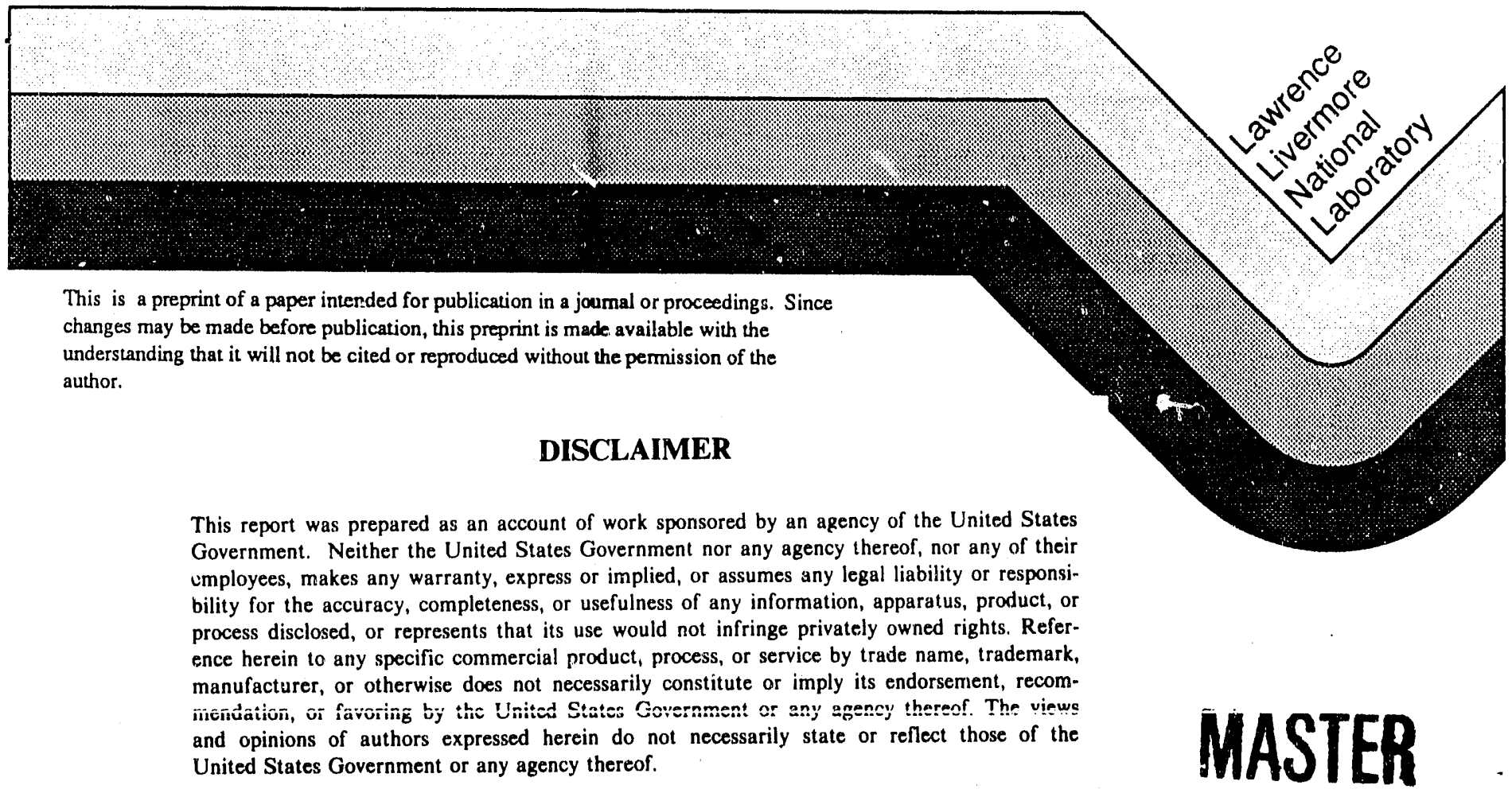


DISCLAIMER

This document was prepared as an account of work sponsored by an agency of the United States Government. Neither the United States Government nor the University of California nor any of their employees, makes any warranty, express or implied, or assumes any legal liability or responsibility for the accuracy, completeness, or usefulness of any information, apparatus, product, or process disclosed, or represents that its use would not infringe privately owned rights. Reference herein to any specific commercial products, process, or service by trade name, trademark, manufacturer, or otherwise, does not necessarily constitute or imply its endorsement, recommendation, or favoring by the United States Government or the University of California. The views and opinions of authors expressed herein do not necessarily state or reflect those of the United States Government or the University of Californiz, and shall not be used for advertising or product endorsement purposes. 


\title{
LAYER FORMATION IN CUNi/C X-RAY OPTICS
}

\author{
A.F. JANKOWSKI* AND D.G. STEARNS** \\ * Chemistry \& Materials Science and **Advanced X Ray Optics Program, Lawrence \\ Livermore National Laboratory, P.O. Box 808, Livermore, California 9455()
}

\begin{abstract}
A series of $\mathrm{Cu} / \mathrm{C}$ and $\mathrm{CuNi} / \mathrm{C}$ multilayer films are prepared for potential use as normal incidence $\mathrm{X}$-ray reflectc-s. The use of a metal alloy layer is intended to enhance layer formation without metastable metallic carbide formation. The films are characterized both in composition and structure. Addition of $\mathrm{Ni}$ to the $\mathrm{Cu}$-rich layer is seen to markedly improve the formation of continuous metal layers.
\end{abstract}

\section{INTRODUCTION}

Multilayer coatings for $\mathrm{x}$-ray optics are becoming increasingly important in applications as $\mathrm{x}$-ray telescopes and soft $\mathrm{x}$-ray projection lithography $[1,2]$. A primary goal is to maximize normal incidence reflectivity for these uses. For example, theoretical reflectivities as high as $50 \%$ are attainable at a $4.5 \mathrm{~nm}$ wavelength for several metal/carbon multilayer systems (Fig.1). To achieve such high reflectivities requires that the repeat period be short and that the layers be continuous, smooth and the interfaces be compositionally abrupt. Unfortunately, these requirements are usually incompatible. Metals with Limited carbon solubility (e.g. $\mathrm{Ni}, \mathrm{Cr}, \mathrm{Co}$, Fe) often form metallic carbides. These carbon-metal systems are expected to react at the interfaces. Multilayers then result with both rough interfaces and a broadening of the composition gradient. On the other hand, metals with virtually no carbon solubility (e.g. $\mathrm{Cu}$ ) will not react. These metals have low wettability on $C$. Layering is unexpected whereas discontinuous metal clusters in a $\mathrm{C}$ matrix are most probable. A modified carbon solubility is therefore preferable for controlled surface wettability, the kinetic suppression of compound formation and consequently the promotion of stable layer formation.

Since the conventional method of multilayer synthesis involves a sputter deposition process, metastable phase formation can occur. The interface roughness found in $\mathrm{Ni} / \mathrm{C}$ multilayers may consequently be attributable to the tendency for metastable metallic carbide (i.e. $\mathrm{Ni}_{3} \mathrm{C}$ ) formation. Attempts to avoid metallic carbide formation by alloying the carbon layer directly have been successful, for example through the replacement of carbon with amorphous boron-carbide $\mathrm{B}_{4} \mathrm{C}[3,4]$. However, boron additions are not always desirable since boron may act as an absorber of $x$ rays (as for the $4.5 \mathrm{~nm}$ wavelength) and therefore greatly reduce reflectivity from the initial design standpoint. It is therefore proposed that simple alloying of the (Ni) metal layer may inhibit interface compound formation with each carbon layer.

The reaction between $\mathrm{Cu}$ and $\mathrm{C}$ is opposite to that with $\mathrm{Ni}$ and $\mathrm{C}$. Nickel will tend to wet $\mathrm{C}$ and form a metastable compound whereas $\mathrm{Cu}$ will apparently not even wet a carbon surface and thereby cluster. The $\mathrm{Cu}-\mathrm{Ni}$ system features continuous solid solubility. Addition of $\mathrm{Ni}$ to the $\mathrm{Cu}$ layers may promote wettability, yet inhibit metastable carbide formation. Therefore, competition between surface energy effects - compound formation versus limited wetability, should ideally lead to a $\mathrm{CuNi} / \mathrm{C}$ multilayer with morphologically sharp interfaces and smooth layers which are well suited for $4.5 \mathrm{~nm} x$ ray normal incident reflection.

\section{EXPERIMENTALS}

The multilayer coatings are prepared by sputter deposition. A nominal 5 mTorr working gas pressure of argon is used to sputter $>0.99994$ targets from circumferentially arranged planar magnetrons operated in the do mode onto rotating silicon substrates situated $20 \mathrm{~cm}$ above each collimated target surface [5]. Under these conditions the sputtered neutrals are essentially 


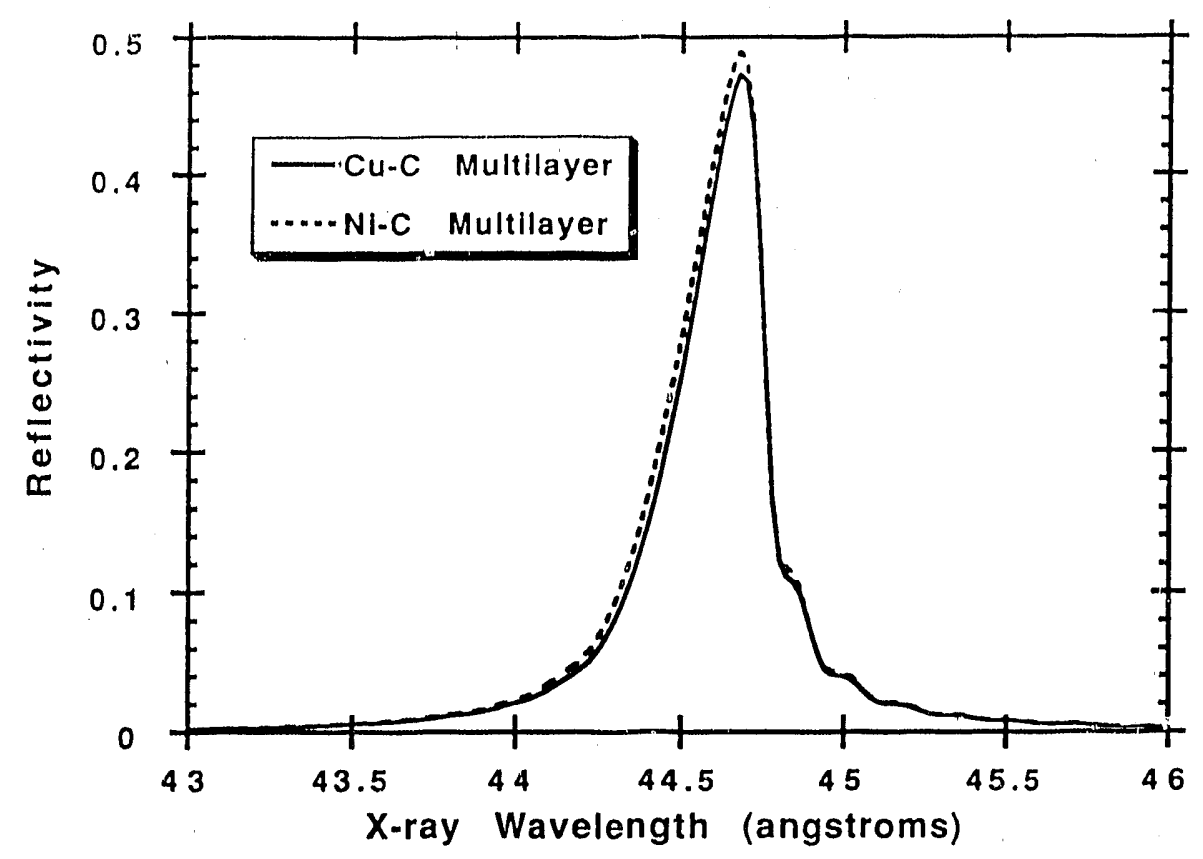

Fig. 1. The normal incidence reflectivity of $\mathrm{Cu} / \mathrm{C}$ and $\mathrm{Ni} / \mathrm{C}$ are plotted as a function of $x$-ray wavelength for ideal multilayers with 250 layer pairs and a $2.24 \mathrm{~nm}$ repeat period, in which the metal to layer pair thickness ratio is 0.4 .

'thermalized' $[6,7]$ and strike the substrate surface at near normal incidence. Deposition rates $(<0.2 \mathrm{~nm} / \mathrm{s})$ and total accumulation are monitored using $6 \mathrm{MH}^{\mathrm{r}} \mathrm{z}$ Au coated quartz crystals. The $\mathrm{Cu}_{\mathrm{x}} \mathrm{Ni}$ alloy layer, which constitutes $40 \%$ of the layer pair thickness, is formed from codeposition of a $6.35 \mathrm{~cm}$ diameter composite target. The design structure for normal incidence reflection of $4.5 \mathrm{~nm} x$ rays is a $2.24 \mathrm{~nm}$ layer pair with a $0.89 \mathrm{~nm}$ thick metal layer (Fig.1).

The layer formation is characterized using grazing incidence $x$-ray diffraction (XRD), transmission electron microscopy (TEM) and Auger electron spectroscopy (AES) coupled with depth profiling. A standard powder diffractometer is operated in the $\Theta / 2 \Theta$ mode using a graphite monochromator and $8.0 \mathrm{KeV} \mathrm{Cu}$ radiation. The coatings are prepared in cross-section for TEM viewing. Image formation is accomplished using amplitude (and unavoidable phase) contrast. AES atomic concentration profiles of the coatings are measured using characteristic peak (920 eV Cu and $783 \mathrm{eV} \mathrm{Ni}$ ) intensity data accumulated in the derivative mode.

\section{RESULTS}

The first series of structures examined are formed by sequential deposition of pure $\mathrm{Cu}$ and C. No layers are evident in these films. Repeat periods as large as $3 \mathrm{~nm}$ were attempted in this series. TEM bright field imaging (Fig.2a) reveals the $\mathrm{Cu}$ clustering into polycrystalline aggregates as a result of the deposition process. The clustering of $\mathrm{Cu}$ also evidences in the AES depth profile (Fig.3a).

The second series of films are formed by placing a $3 \mathrm{~cm}$ diameter $\mathrm{Ni}$ cap within the erosion ring of the C.u sputter target. In this way, a Cu. ${ }_{9} \mathrm{Ni}_{.1}$ composition metal alloy is formed (Fig. 3 b). No layers are formed in the second films series for attempted repeat periods as large as $3 \mathrm{~nm}$. The Cu no longer clusters, however, but appears uniformly dispersed in a C-matrix (Fig.2b). The Ni has been an effective wetting agent for $\mathrm{Cu}$ on $\mathrm{C}$.

The third series of films are made with a $\mathrm{Ni}$ target superpositioned on top of a $\mathrm{Cu}$ target. The Ni target has $9.5 \mathrm{~mm}$ holes every $60^{\circ}$ in a $3.2 \mathrm{~cm}$ diameter circle. This produces a sputtered $\mathrm{Cu} .{ }_{7} \mathrm{Ni} .3$ metal alloy (Fig.3c). The increased $\mathrm{Ni}$ concentration should further promote, enhanced wetting of the Cu-rich 'layers' on $\mathrm{C}$. Near continuous $\mathrm{Cu}-\mathrm{Ni}$ layers are found (Fig.2c) sequiential to $C$ layers as in a 30 layer pair, $3.43 \mathrm{~nm}$ repeat period multilayer. Layer formation is enhanced, as found from XRD, for repeat periods greater than $2.5 \mathrm{~nm}$ (Fig.4). 


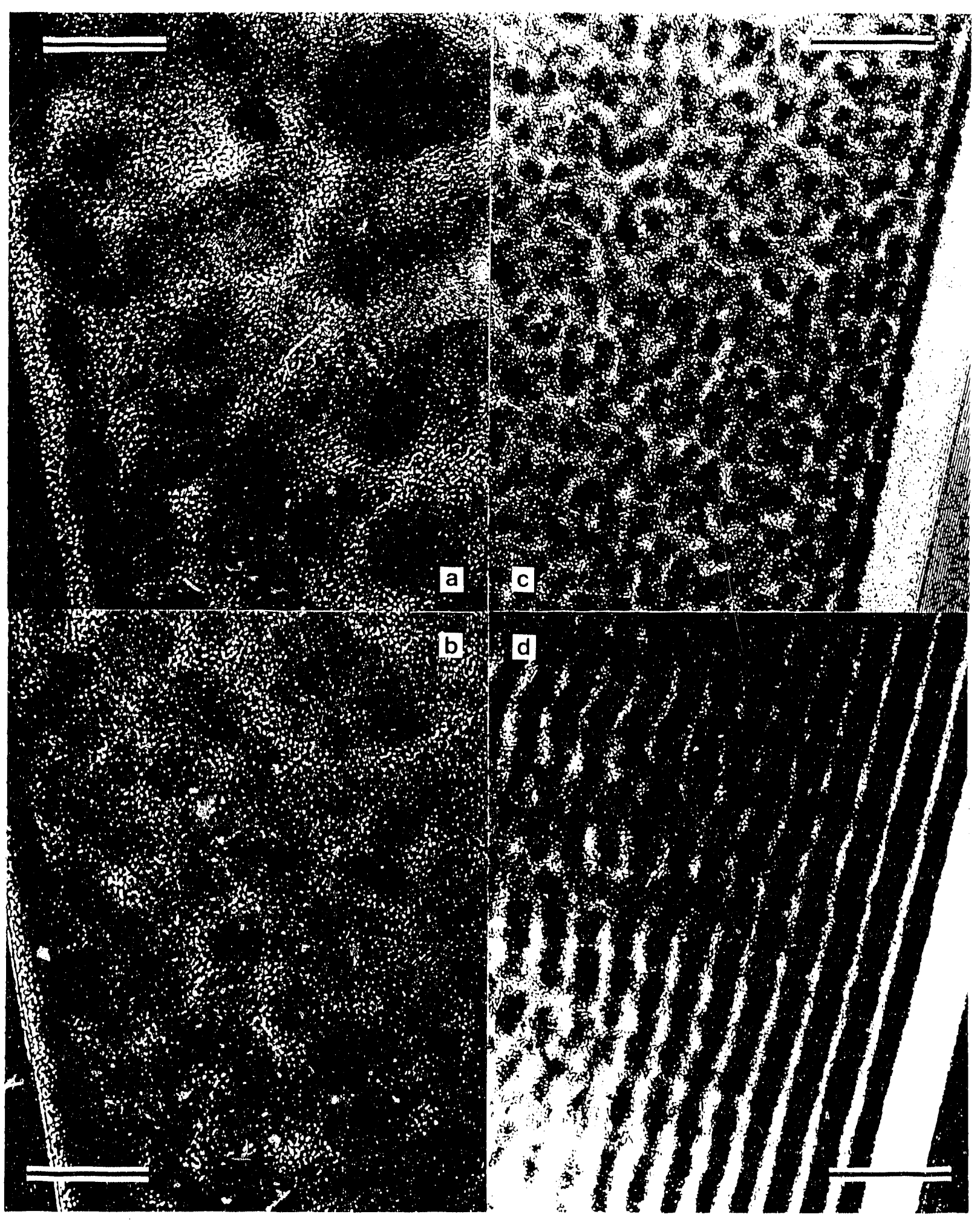

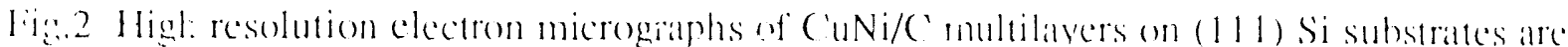
viewed in coss section. ('uclusters (dark regions) in a c-matrix (light region) are found in a)

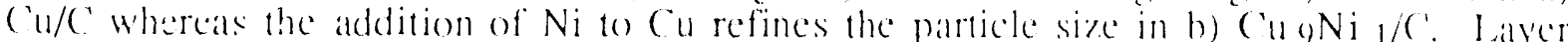
formation is covident with the further addition of $\mathrm{Ni}$ in (c) a $3.43 \mathrm{~mm}$ ( ${ }^{4}, 7 \mathrm{Ni}, 3 / \mathrm{C}$ and for $\mathrm{d}$ ) a 4.3.jumi Ni/c struciare. Bar 1.3nm. 

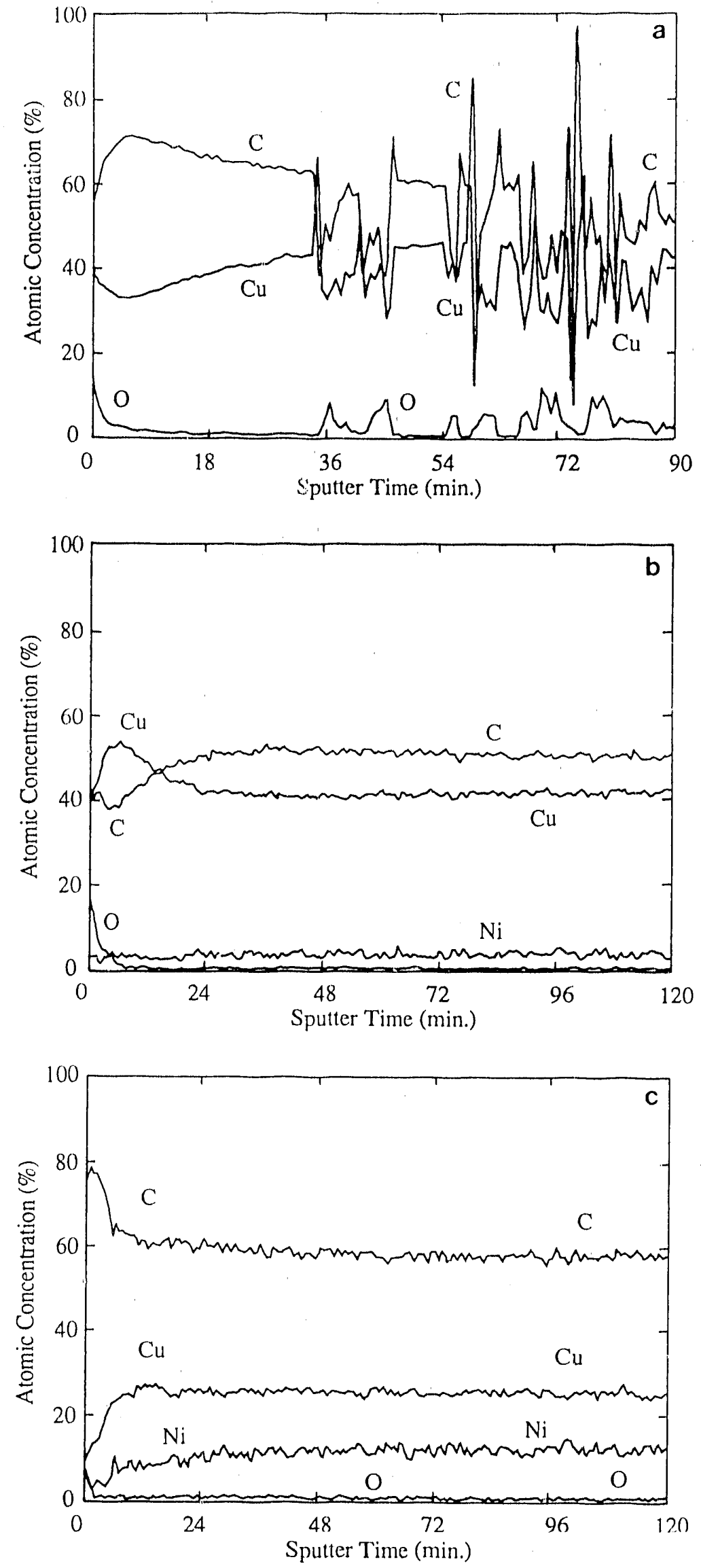

Fig.3. Auger electron concentration profiles of the $\mathrm{CuNi} / \mathrm{C}$ multilayers reveal the average composition of each film over a $25 \mathrm{~mm}^{?}$ area as a function of sputter time (i.e. depth). In a) the $\mathrm{Cu} / \mathrm{C}$ 'multilayer', profiling through the $\mathrm{Cu}$ clusters (Fig.2a) is evidenced by spikes in the depth profile. In b) the $\mathrm{Cu} .{ }_{9} \mathrm{Ni}_{1} / \mathrm{C}$ 'multilayer', the addition of $\mathrm{Ni}$ to the $\mathrm{Cu}$ layer has reduced the size of the metal clusters (Fig.2b) resulting in the disappearance of concentration spikes as evidenced for $\mathrm{Cu} / \mathrm{C}$. In $\mathrm{c}$ ) the $\mathrm{Cu} .7 \mathrm{Ni} .3 / \mathrm{C}$ multilayer, the further increase in $\mathrm{Ni}$ content has resulted in a layered structure (Fig.2c). The last two layer pairs of the film are almost discernable in the first $30 \mathrm{~min}$. of the depth profile. 


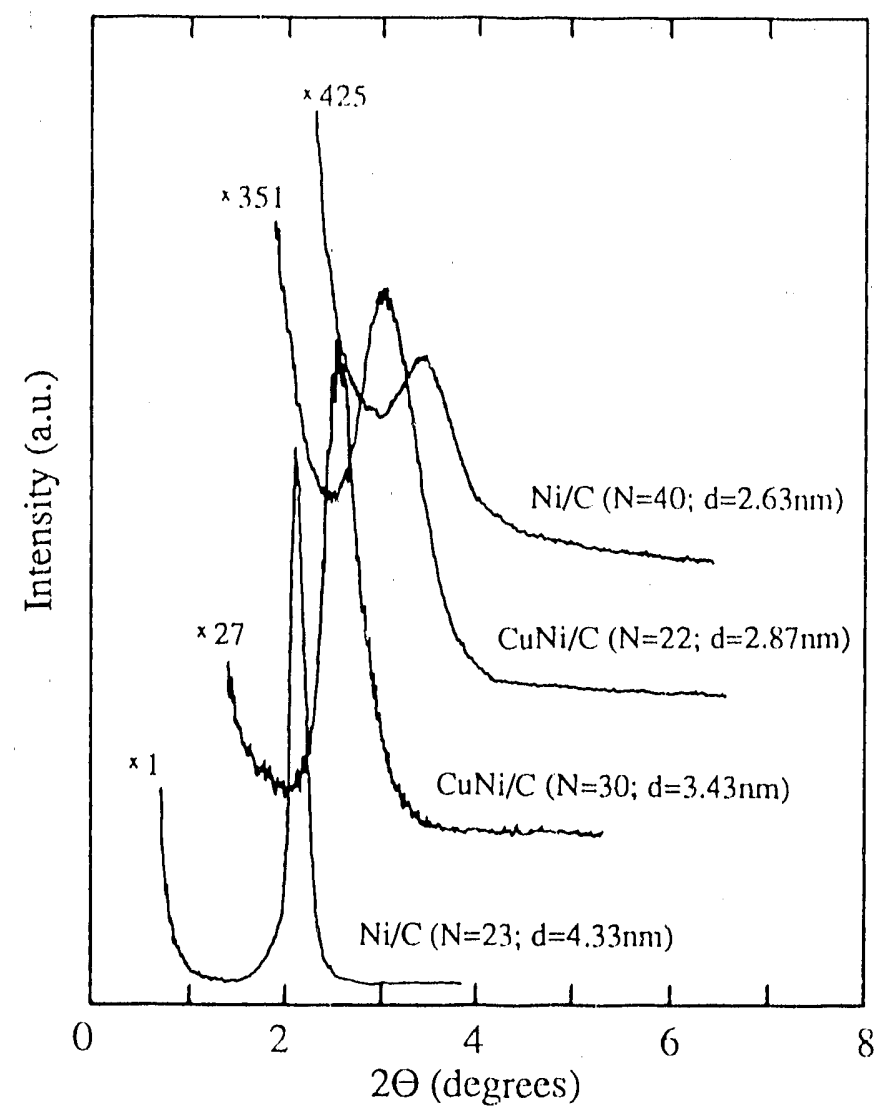

Fig.4. Intensity of the grazing incidence reflections from $\mathrm{CuN} / / \mathrm{C}$ multilayers are plotted, as determined from $\Theta / 2 \Theta$ scans in a powder diffractometer using $8.0 \mathrm{KeV} \mathrm{Cu}$ radiation and a graphite monochromator. The onset of layer formation is seen for both $\mathrm{Ni} / \mathrm{C}$ and $\mathrm{Cu} .7 \mathrm{Ni} .3 / \mathrm{C}$ as an order of magnitude increase in the reflectivity is measured for layer pairs increasing from $<2.6$ to $>3.3 \mathrm{~nm}$.

The grazing incidence diffraction scans clearly show the intensity of the $\mathrm{Cu}_{7} \mathrm{Ni}_{3} / \mathrm{C}$ first order reflection increasing by more than an order of magnitude as the layer pair increases from 2.87 to $3.43 \mathrm{~nm}$.

The fourth series of structures are formed by seuquential deposition of pure $\mathrm{Ni}$ and $\mathrm{C}$. Layer formation becomes evident, as for $\mathrm{Cu} .7 \mathrm{Ni} .3 / \mathrm{C}$, at layer pairs preater than $2.5 \mathrm{~nm}$ (Fig.4). The diffraction scan of a $3.27 \mathrm{~nm} \mathrm{Ni} / \mathrm{C}$ multilayer is nearly identicai io the $3.43 \mathrm{~nm} \mathrm{Cu} .7 \mathrm{Ni} .3 / \mathrm{C}$ multilayer with respect to both peak intensity and width. Similar observations of interlayer roughness (Fig.2d) are apparent from TEM, as well.

\section{ANALYSIS}

It is interesting to consider the implications of our current findings with respect to the surface energy relationships of the $\mathrm{CuNi} / \mathrm{C}$ multilayer system. The condition to form a stable layer is the result of the tendency for material $\mathrm{X}$ to successfully welt the surface of material $\mathrm{Y}$. A general expression for this condition using the free surface energy $\emptyset$ is

$$
\varnothing_{X}-\varnothing_{Y}+\varnothing_{X / Y}<0
$$

where $\emptyset_{X}$ and $\varnothing_{Y}$ are the free surface energies of materials $X$ and $Y$, and $\varnothing_{X Y}$ is the energy associated with the $\mathrm{X}-\mathrm{Y}$ interface formation. The calculated surface energies [8] for $\mathrm{Cu}, \mathrm{Ni}$ and $\mathrm{C}$ are $\varnothing_{\mathrm{Cu}}=1.93 \mathrm{~J} / \mathrm{m}^{2}, \varnothing_{\mathrm{Ni}}=2.36 \mathrm{~J} / \mathrm{m}^{2}$ and $\varnothing_{\mathrm{C}}=0.51 \mathrm{~J} / \mathrm{m}^{2}$. (Alihough different in absolute magnitude, a similar difference between $\mathrm{Cu}\left(1.27 \mathrm{~J} / \mathrm{m}^{2}\right)$ and $\mathrm{Ni}\left(1.73 \mathrm{~J} / \mathrm{m}^{2}\right)$ is measured for liquid element, surface tensions [9].]

Since $\mathrm{Cu}$ and $\mathrm{C}$ are immiscible, we can assume that the $\mathrm{Cu}$ on $\mathrm{C}$ interface energy $\varnothing_{\mathrm{Cu} / \mathrm{C}}$

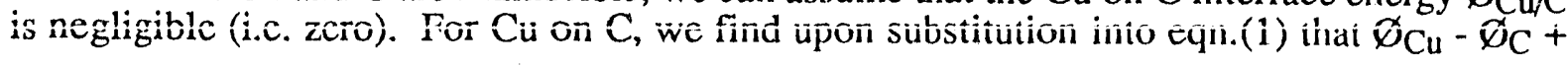


$\emptyset_{\mathrm{Cu} / \mathrm{C}}$ equals $1.4 \mathrm{~J} / \mathrm{m}^{2}$. The predicted increase in surface energy for the $\mathrm{Cu}$ on $\mathrm{C}$ case shows that layer growth is energetically unfavorable, in agreement with our observations of the $\mathrm{Cu} / \mathrm{C}$ 'multilayer' structures (Fig.2a). Since layering, however, is indeed observed in Ni/C (Fig.2d), the eqn.(1) inequality must be valid. Therefore, upon eqn.(1) substitution we find $\varnothing_{\mathrm{Ni} / \mathrm{C}}$ is negative and that $\mid \varnothing_{\mathrm{Ni} / \mathrm{C}}>1.8 \mathrm{~J} / \mathrm{m}^{2}$. This is not unexpected since $\mathrm{Ni}$ and $\mathrm{C}$ are soluble suggesting $\varnothing_{\mathrm{Ni} / \mathrm{C}}$ must be less than zero.

The surface energy of the $\mathrm{Cu}-\mathrm{Ni}$ alloys, $\varnothing_{\mathrm{Cu}-\mathrm{Ni}}$, should be between the values of the pure elements. The fact that we have observed improved layer formation upon the addition of $\mathrm{Ni}$ to $\mathrm{Cu}$ implies that the increase in surface energy is offset by a large (negative) $\mathrm{Cu}-\mathrm{Ni}$ on $\mathrm{C}$ interface energy $\varnothing_{\mathrm{Cu}-\mathrm{Ni} / \mathrm{C}}$. From eqn:(1), we find that

$$
\varnothing_{\mathrm{Cu}-\mathrm{Ni}}+\varnothing_{\mathrm{Cu}-\mathrm{Ni} / \mathrm{C}}<0.51 \mathrm{~J} / \mathrm{m}^{2}
$$

The observed improvement in layering with increasing $\mathrm{Ni}$ content is strong evidence of a

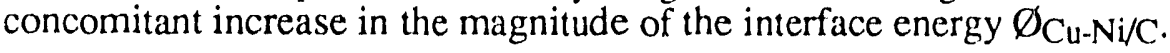

\section{SUMMARY}

The use of $\mathrm{Ni}$ alloying with $\mathrm{Cu}$, by cosputtering, has lead to stable layer formation in the $\mathrm{CuNi} / \mathrm{C}$ multilayer system. Pure $\mathrm{Cu}$ is found to cluster rather than form layers. The use of $\mathrm{Ni}$, in solid solution with $\mathrm{Cu}$, enhances the wettability of $\mathrm{Cu}$ on $\mathrm{C}$. Metastable metallic carbide(s) formation is avoided using $\mathrm{CuNi}$ rather than pure $\mathrm{Ni}$. This should ultimately result in higher reflectivities for $\mathrm{CuNi} / \mathrm{C}$ (than for $\mathrm{Ni} / \mathrm{C}$ ) since broadening of the composition gradient is reduced by the suppression of interface compound formation. The procedure of creating stable metal alloy layers, by balancing competing surface energy effects between constituents, is promising for producing short period multilayer $\mathrm{x}$-ray optics.

\section{ACKNOWLEDGMENTS}

We thank L.R. Schrawyer for the AES depth profiles, L.J. Summers for the XRD scans and M.A. Wall for the TEM micrographs. This work was performed under the auspices of the United States Department of Energy by Lawrence Livermore National Laboratory under contract \#W-7405-Eng-48.

\section{REFERENCES}

1. N.M. Ceglio, Journal of X-Ray Science and Technoiogy 1, 7 (1989).

2. J. Harvey, W. Zmek and C. Ftaclas, Optical Engineering 29, 603 (1990).

3. A. Jankowski, L. Schrawyer, M. Wall, W. Craig, R. Morales and D. Makowiecki, Journal of Vacuum Science Technology A7, 2914 (1989).

4. A. Jankowski, L. Schrawyer and M. Wall, Journal of Applied Physics 68 (1990) in press.

5. A. Jankowski and D. Makowiecki, in SPIE Vol. 984 X-Ray Multilayers for Diffractometers, Monochromators and Spectrometers (1988) 64.

6. W.D. Westwood, Materials Research Society Bulletin 13 (12), 46 (1988).

7. R.E. Somekh, Journal of Vacuum Science Techriology A 2, 1285 (1984).

8. L.Z. Mezey and J. Giber, Japanese Journal of Applied Physics 21, 1569 (1982).

9. CRC Handbook of Chemistry and Physics 65th Edition, ed. R.C. Weast (CRC Press, Boca Raton, 1985) F20-26. 

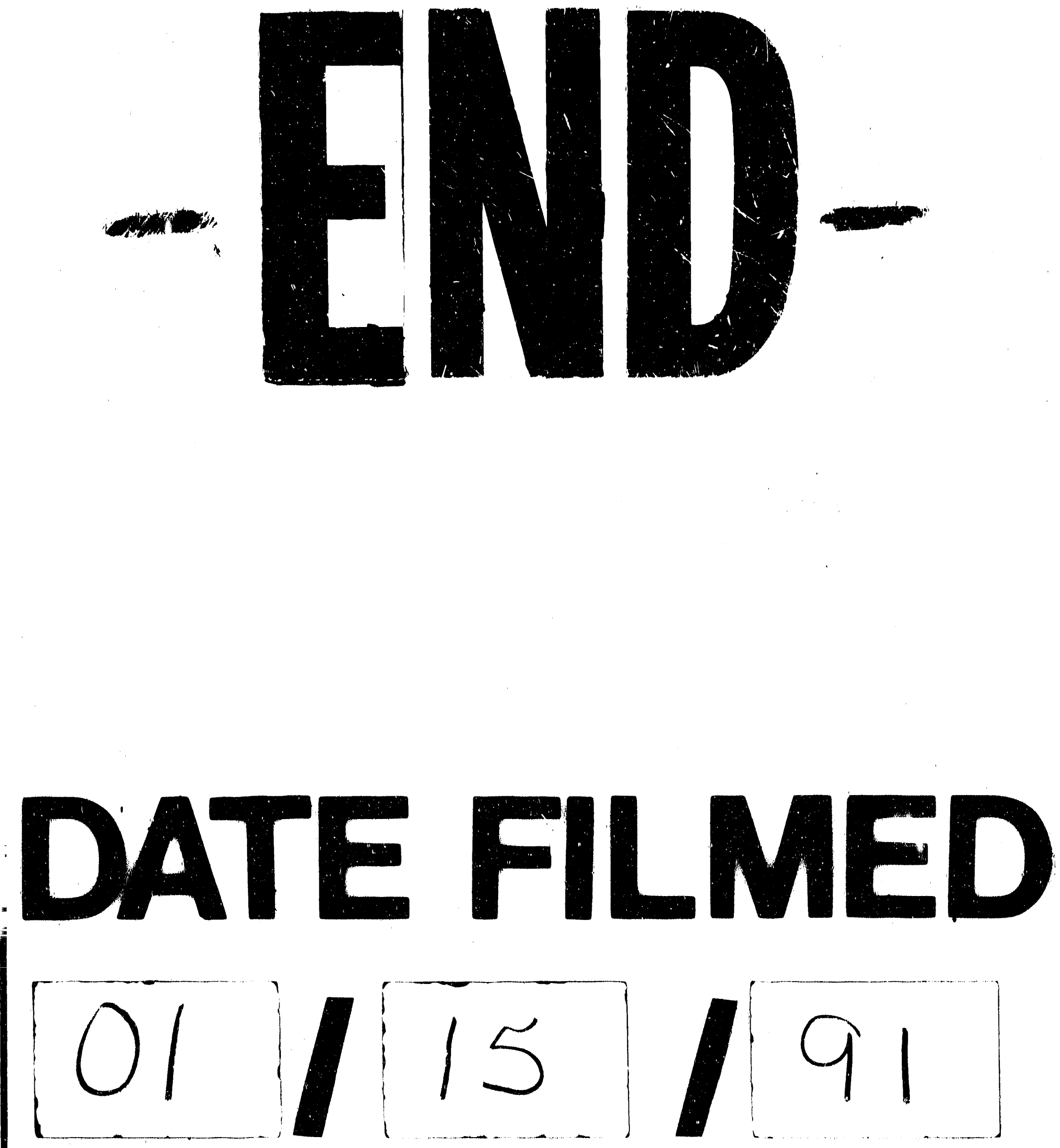
